\title{
Cognitive Task Complexity and L2 Narrative Writing Performance
}

\author{
Ali Akbar Khomeijani Farahani \\ English Department, Faculty of Foreign Languages and Literatures, University of Tehran, Tehran, Iran \\ Email: farahani@ut.ac.ir \\ Seyed Reza Meraji \\ University of Tehran, Tehran, Iran \\ Email: rmeraji@ut.ac.ir
}

\begin{abstract}
The present study was an attempt to chart the effects of two task design features, namely pre-task planning time and immediacy on written narrative performance. This is of pronounced importance since the synergistic effects of these two task features have gone largely unheeded in task-based research except for a smattering of studies (e.g., Gilabert, 2007). Accordingly, 123 participants were assigned to one of the 4 groups in the study, i.e., No planning \& Here-and-Now, No planning \& There-and-Then, Planning \& Here-and-Now, and Planning \& There-and-Then to write out a narrative task based on a series of pictures. The participants' output was coded and measured for grammatical accuracy, syntactic complexity, lexical complexity, and fluency. Results showed that only pre-task planning time significantly promoted grammatical accuracy albeit with a small effect size. Pre-task planners complexified their discourse more than no-planners. In addition, displacedness of time and space coupled with pre-task planning led to significantly higher gains in syntactic complexity. However, lexical complexity measures did not yield any significant results across the groups of participants. Finally, both provision of pre-task planning time and immediacy of time and space led to significantly more fluent production.
\end{abstract}

Index Terms - pre-task planning time, immediacy, accuracy, syntactic complexity, lexical complexity, fluency

\section{INTRODUCTION}

Roused by the vain quest for finding a nostrum to the mounting need of communication across the world, which has gone partially unfulfilled by the orchestration of both historic and current teaching paradigms, the fields of second language acquisition and language pedagogy in the 1970s were signposted by a flurry of research studies which challenged the choice of traditionally defined formal units of syllabus and alternatively opting for tasks to be capitalized on, developed and sequenced in order to approximate the demands of real world target tasks (Prabhu, 1987; Skehan, 1998). The resultant task-based craze spurred SLA researchers on to clinically define, experiment with, explore, and sequence the principal units of task-based instruction, tasks, in order to discern if they had any impact on learners' performance and development and if any, how they could be modulated to nudge learners' performance to measure up to the processing demands of real world performance.

This conviction begot a new strand of research into differential effects of modulation of task features on linguistic performance, namely information processing research. In information processing research on tasks, tasks are manipulated along their inherent complexity, their perceived difficulty, or the conditions under which they are completed in order for researchers to measure their effects on learners' comprehension, production, or development.

The role of attention and how it can be allocated to different aspects of production (accuracy, complexity, and fluency) has been a cornerstone of this line of research. Grounding their research in limited attentional capacity model (Huitt, 2003; Skehan, 1998; Skehan \& Foster, 2001; VanPatten, 1992, 2002), one camp of researchers are in the conviction that in the wake of learners' limited attentional resources, discourse engendered by L2 learners would favor one area of performance (meaning) at the expense of another (form). This is the perspective which has garnered the most attention among task researchers. Based on empirical evidence for planning studies, Skehan (1998) and Skehan and Foster (1999, 2001) maintain that tradeoffs transpire between accuracy and complexity with fluency unscathed. A corollary of this proposal, which has morphed into a driving force behind task studies in the information processing tradition, is that learners' attention can be selectively channeled to certain aspects of production in which they are lacking so as to strike a balance between the three areas of production, i.e., accuracy, complexity, and fluency.

Pitted against the former proposal is the Cognition Hypothesis, also known as the Triadic Componential Framework, advanced by Robinson (2001a, 2001b, 2007) which collapses task design features into three categories of task complexity, task conditions, and task difficulty. Task complexity is taken as a host of cognitive factors which is "the result of attentional, memory, reasoning, and other information processing demands imposed by the structure of the task on the language learner" (Robinson, 2001a, p. 29). Task complexity further falls into resource-directing and 
resource-dispersing dimensions.

The former pertains to task features, increases along which, according to Robinson, direct attentional resources to specific linguistic items of the language. This is based on Givon's (1985) proposal that greater linguistic complexity is latched onto greater functional complexity. This proposition seems at odds with that of Skehan (1998) in which more cognitively demanding tasks are presumed to take a heavier toll on performance than less cognitively demanding ones. Resource-directing dimensions include +/- few elements, +/- Here-and-Now, and +/- no reasoning demands.

On the other hand, the latter dimensions of task complexity are concerned with task features increments along which puts a cramp on attentional resources and working memory, thus, steering attention away from linguistic forms. Robinson's proposal in this regard chimes that of Skehan (1998). The resource-dispersing dimensions include +/pre-task planning time, +/- single task, and +/- prior knowledge.

\section{A. Planning Time Studies}

Historically a processing condition, planning time has for long commanded the attention of task researchers. It is a task feature whose findings have been largely stable across studies (Ellis, 2005). Planning studies more often than not have demonstrated that pre-task planning time fosters fluency and complexity of production. On the other hand, within-task planning has been shown to foster different aspects of performance than those of pre-task planning time. Thus, as Pica (1997) puts it, the study of planning time should be deemed a suitable forum for making a nexus between theory, research and pedagogy in SLA, as provision or absence thereof may aid language production and development.

To date, the majority of planning studies have explored the impact of planning on a single task type, a number of other studies, nonetheless, have examined differentials across several task types (Mehnert, 1998; Skehan \& Foster, 1997; and Wiggleworth, 2001). Despite the fact that the preponderance of story-retelling in task types used in planning studies is conspicuous, an impressive array of other task types such as picture description, giving instructions, personal information exchange, telephone-answering machine messages, giving directions, general discussion questions, and decision making tasks has also been probed. Languages investigated thus far include English in most studies, Dutch (Hulstijn \& Hulstijn, 1984), German (Mehnert, 1998), Spanish (Ortega, 1999), and Mandarin (Ting, 1996).

As explicated in the foregoing, pre-task planning time has conduced to relatively consistent results across studies. Much of the research to date has heralded gains in fluency (e.g., Ellis \& Yuan, 2004; Foster \& Skehan, 1996; Rouhi \& Marefat, 2006; Mehnert, 1998; Yuan \& Ellis, 2003). Complexity has also been shown to be aided through strategic planning (e.g., Ellis \& Yuan, 2004; Foster \& Skehan, 1996; Mehnert, 1998; Ortega, 1999; Yuan \& Ellis, 2003). However, findings with regard to accuracy are mixed.

Yuan and Ellis (2003) bifurcated planning into on-line planning and pre-task planning. It was shown that with respect to fluency, pre-task planners outperformed on-line planners. Regarding complexity measures, both planning groups obtained significantly higher complexified their speech more than no-planners. In terms of lexical variety, pre-task planners significantly outdid on-line planners. Finally, on-line planners generated significantly more accurate discourse than no-planners.

Ellis and Yuan (2004) looked into whether the effects of planning were sustained in narrative writing performance. Fluency results showed that pre-task planning conduced to higher gains in fluency. Planning in both planning groups engendered higher levels of syntactic complexity. In terms of syntactic variety, pre-task planners outdid no planners and on-line planners. In general terms, data gleaned from the questionnaire and interviews indicated that pre-task planners tried to understand the pictures, plan the organization of the narrative, plan its content in the time allocated for planning, and attended to language forms during the period earmarked for the actual performance, while no-planners and on-line planners needed to juggle these four aspects simultaneously.

Delving deeper into the role of different proficiency levels and pre-task planning in oral narrative performance, Kawauchi (2005) investigated three proficiency level groups' performance on narrative tasks. Planning was operationalized using three pre-task activities of rehearsal, reading a related L2 model, and writing a draft, for all of which 10-minute planning time was allowed. Participants first performed an unplanned version of the task. Having done a planning activity prior to the real performance, the participants executed the same task at the end.

It was found that strategic planning had promoted fluency, especially for the high proficiency group. However, the advanced proficiency group's fluency deteriorated by the provision of planning. In terms of complexity, the advanced group did not benefit much from planning. Significant accuracy gains were absent for the advanced group, too. The irregular past forms were the highest scoring accuracy measure for all three groups in the no-planning condition which was significantly promoted for all groups in the planned condition.

Voicing their dissenting view over the foregoing research agenda which has used short-running tasks preceded by the orthodox 10-minute pre-task planning time, Skehan and Foster (2005) examined the sustainability of the effects of strategic planning time during on-line execution of the task. Operationalizing planning at three levels (no planning, 10-minute unguided planning time, and 10-minute guided planning time), they crossed this variable with another task feature, namely introduction of extra information. The researchers found that strategic planning promoted performance in general across all aspects of production. No significant effects were detected for the influence of surprise information on production. In addition, results revealed that enhanced levels of performance could not be maintained for long periods, as learners' performance significantly deteriorated after five minutes of task execution.

In a laboratorial study Rouhi and Marefat (2006) investigated the effect of pre-task planning (three levels of no 
planning in the oral mode, pre-task planning in the oral mode, and on-line planning in the written mode) on the performance of Iranian L2 learners in oral and written modes. It was found that pre-task planning conduced to significantly more fluent language than no planning. With regard to complexity, no significant differences were found across the three planning conditions. Finally, both planning groups significantly generated more accurate production compared to the no-planning group.

Gilabert (2007) explored the synergistic impacts of planning ( 0.50 seconds vs. 10 minutes) and +/- Here-and-Now on L2 oral narratives. The production measure for fluency, pruned speech rate, showed that planned Here-and-Now and Planned There-and-Then tasks conduced to significantly more fluent discourse than the unplanned tasks. As regards syntactic complexity, number of S-nodes per T-unit, no significant differences were registered across the planned and unplanned conditions. Regarding lexical complexity assessed by Guiraud's Index of lexical richness (type/ $/$ tokens), significantly more lexicalized language in the planned conditions was generated in comparison to the unplanned ones. Accuracy measures demonstrated slightly higher levels of accuracy for the planned conditions compared to the unplanned ones.

\section{B. Immediacy Studies}

The +/- Here-and-Now conditions are advanced anchored in evidence that reference to displaced time and space manifests itself at a later stage in the L1 development, given the conception that reference to events in the There-and-Then summons an array of cognitive operations and linguistic resources that are not at a child's disposal (Givon, 1985). This reference to There-and-Then calls for a certain gambit of conceptual ability to retrieve and to represent displaced events as well as the procedural ability to manage a conversation so as to provide the interlocutor with chances to shape and promote shared pragmatic presuppositions (Robinson, 1992). On the other hand, this presupposes access to a slew of code features, notably tense and aspect, to encode former events at a mutually agreed time (Wenzell, 1989). Hence, a language learner desiring to make displaced reference should be endowed with conceptual, procedural, and code knowledge.

Robinson (1995) concurs Givon's (1985) proposition on the grounds that the context-reduced There-and-Then is deemed to burden the limited attentional capacity of the learner, as the learner strives to infer and retrieve the stored information, whereas the Here-and-Now allows him/her to focus on fluent production.

These conditions can also be conceptualized in terms of memory demands (Ishikawa, 2007). The +/- Here-and-Now conditions are delineated by distinctive memory demands through the access to or absence of context support. This bears on how information is processed in the mind, as in light of the absence of visual support (- Here-and-Now), learners have to commit the plotline to memory; subsequently, they have to make an effort to retrieve the needed information from memory, and cohere the information into a unified narrative. Thus, this extra effort after understanding the narrative expands semantic representations in advance of task performance which may assist deeper semantic processing, hence complexification of the output.

In a seminal work, Robinson (1995), following Givon's (1985) remark that greater structural complexity is hitched to greater functional complexity, homed in on the dichotomy between Here-and-Now and There-and-Then. The Here-and-Now group outperformed the There-and-Then group almost significantly in terms of fluency. The lexical complexity measure demonstrated that more complex tasks (There-and-Then) would elicit more complex language. Accuracy was also encouraged by the There-and-Then task.

Ishikawa (2007) took up +/- Here-and-Now as the independent variable in his narrative writing study. The researcher found significant higher accuracy gains for target-like use of articles in the There-and-Then condition. Syntactic complexity scores were significantly higher in the There-and-Then condition. Lexical variation showed relatively higher use of different word types in the There-and-Then. With regard to fluency, the There-and-Then condition conduced to the generation of less fluent language.

Another Here-and-Now inquiry was conducted by Gilabert (2007) on L2 oral narrative discourse through crossing two task complexity indices (+/- Here-and-Now and +/- planning time). Accuracy was fostered in the - Here-and-Now. Regarding syntactic complexity, the prediction that more complex tasks generate higher syntactic complexity was not borne out. As regards lexical complexity, the participants produced a less lexically complex story in the complex conditions (There-and-Then). Finally, the production measure for fluency exhibited more dysfluent speech in the There-and-Then conditions.

Rahimpour (2007) in a further study explored the effects of manipulation of $+/$ - Here-and-Now on oral performance of EFL learners. The results indicated that the participants' accuracy improved significantly in the complex task (There-and-Then). However, the Here-and-Now condition gave rise to more fluent and more complex language.

The present study sought to account for the effects of manipulating task complexity along two dimensions of $+/-$ Planning time and +/- Here and Now (Robinson, 2001b) on L2 writing performance in order to test and compare Robinson's Cognition Hypothesis (Robinson, 2001a, 2001b, 2007) and Skehan and Foster's Limited Attentional Capacity Model (Skehan, 1998; Skehan and Foster, 1999, 2001). This inquiry seems to be of consequence since, to the best of the researchers' knowledge, no study to date has measured the possible performance differentials of the manipulation of both resource-directing dimensions (+/- Here and Now) and resource-dispersing dimensions (+/Planning time) of task complexity on L2 written performance.

If the simultaneous manipulation of resource-directing and resource-dispersing dimensions has different bearings on 
performance from what have been previously found investigating each separately, the corresponding proposals should factor in the potential effects of manipulation differentials of both resource-directing and resource-dispersing dimensions. Secondly, it is sought to see if the predictions made by the Cognition Hypothesis and Limited Attentional Capacity Model hold for the impact of task index differentials on narrative writing tasks, as they have on oral narratives.

The following research questions have led the course of the present investigation:

1. Does simultaneous manipulation of task complexity along planning time and immediacy affect written production in terms of grammatical accuracy?

2. Does simultaneous manipulation of task complexity along planning time and immediacy affect written production in terms of syntactic complexity?

3. Does simultaneous manipulation of task complexity along planning time and immediacy affect written production in terms of lexical complexity?

4. Does simultaneous manipulation of task complexity along planning time and immediacy affect written production in terms of fluency?

\section{Methodology}

\section{A. Participants}

One hundred twenty three Iranian intermediate EFL learners of English, 73 males and 50 females, aged between 18 and 45, from twelve intact mixed sex classes served as the participants in this study. The participants had been selected from a pool of 175 Iranian EFL learners who had been placed in the same level of English class by either an institutional placement test or a final examination composing of a written examination and an oral interview at Farhikhtegane Daneshgah Institute. The participants' experience with English was limited to their instructional setting. At the time of data collection, the participants were studying New Interchange 2.

Following a recommendation in Ellis \& Yuan's (2004) study, in order to "ideally" ensure homogeneity of the groups studied in terms of general proficiency, a similar narrative task as the one used in the main study minus planning time and in the + Here-and-Now was administered as a proficiency test and subsequently the participants' written output was rated and further assessed in terms of analytic ratings, grammatical accuracy, structural complexity, and fluency. Hence, the present study used both program level and a writing pre-test to check the homogeneity of the groups of participants. In terms of the latter, the participants were collapsed into four groups for which no significant differences were found across the groups of participants in terms of analytic ratings, grammatical accuracy, syntactic complexity, and fluency.

\section{B. Materials}

The structured narrative task used in this study consisting of twelve picture strips was taken from Quino (Salvador, 1985). The reasons behind choosing a narrative task were their being non-interactive and thus openness to greater control (Tavakoli \& Skehan, 2005) and also comparison with studies of planning and +/- Here-and-Now which have used comparable tasks (e.g., Foster \& Skehan, 1996; Gilabert, 2007; Rahimpour, 2002, 2007; Robinson, 1995).

\section{Procedures}

The twelve groups of participants collapsed into four conditions; thereby rendering four groups for data collection (See Table 1).

Condition 1: + Here-and-Now \& + Planning

Condition 2: - Here-and-Now \& + Planning

Condition 3: + Here-and-Now \& - Planning

Condition 4: - Here-and-Now \& - Planning

Following Gilabert (2007), Ishikawa (2007), Rahimpour (2002, 2007), and Robinson (1995), the context-supported + Here-and-Now in the present study was the condition in which learners had recourse to picture series throughout task completion so as to prompt the participants to refer to the immediate environment of the narrative and the participants had to narrate the events in the present tense (Appendix A). Conversely, context-reduced - Here-and-Now was when learners had no access to the picture strips after pre-task planning time so as to urge reference to the absent environment and the participants had to narrate the story as if happening in the past (Appendix B).

As regards pre-task planning time, another task feature manipulated, learners in the planning groups had 14 minutes to complete the task, the time of which had been established through a pilot study plus 10 minutes for pre-task planning. In contrast, in the no planning groups, in spite of the fact that learners had 14 minutes to execute the task, they had 50 seconds to look at the picture set to make out the story before writing out the story embedded in the pictures. The time for pre-task planning was selected following Ellis \& Yuan (2004), Foster \& Skehan (1996), Gilabert (2007), Mehnert (1998), Ortega (1999), and Yuan \& Ellis (2003). During pre-task planning, participants were supposed to plan their writing in terms of language, organization, and content, following foregoing research (e.g., Ellis \& Yuan, 2004; Foster \& Skehan, 1996); however, no specific guidance with regard to planning for form, organization, or content was provided. A note sheet was provided for learners to plan their production while looking at the task. The piece of paper was collected upon the completion of 10 minutes of planning, with learners' prior knowledge, so as to preclude any attempts at using the exact lexical items in the writings, following previous research (e.g., Ellis \& Yuan, 2004). 
TABLE 1

EXPERIMENTAL DESIGN

\begin{tabular}{|c|c|c|c|}
\hline $\begin{array}{l}\text { Here-and-Now } \\
\text { No-planners }\end{array}$ & Here-and-Now Planners & There-and-Then No-planners & There-and-Then Planners \\
\hline $\mathrm{G} 1(\mathrm{n}=30)$ & $\mathrm{G} 2(\mathrm{n}=31)$ & $\mathrm{G} 3(\mathrm{n}=30)$ & $\mathrm{G} 4(\mathrm{n}=32)$ \\
\hline 50 seconds for planning & $\begin{array}{l}10 \text { minutes } \\
\text { for planning }\end{array}$ & 50 seconds for planning & 10 minutes for planning \\
\hline $\begin{array}{l}14 \text { minutes to perform the } \\
\text { task }\end{array}$ & 14 minutes to perform the task & 14 minutes to perform the task & $\begin{array}{l}14 \text { minutes to perform the } \\
\text { task }\end{array}$ \\
\hline $\begin{array}{l}\text { Picture set accessible } \\
\text { during execution }\end{array}$ & $\begin{array}{l}\text { Picture set accessible during } \\
\text { execution }\end{array}$ & $\begin{array}{l}\text { Picture set inaccessible during } \\
\text { execution }\end{array}$ & $\begin{array}{l}\text { Picture set inaccessible } \\
\text { during execution }\end{array}$ \\
\hline
\end{tabular}

Accordingly, having been provided with a piece of paper to write notes upon during the pre-task planning stage, the + Here-and-Now planners were supposed to plan for the ensuing performance over a spell of 10 minutes; however, they were told not to write out the whole story. Following Ellis \& Yuan (2004), Mehnert (1998), and Yuan \& Ellis (2003), the participants in this group had also been notified that their notes would be collected after their pre-task planning time. This procedure was utilized immediately after pre-task planning to ensure that the language produced by the task was produced within the specified time (Ellis \& Yuan, 2004; Yuan \& Ellis, 2003). They were also instructed to write at least 150 words and that the task had to be completed in 14 minutes. Embracing Rouhi and Marefat's (2006) approach, the time limit for task execution was established based on a pilot study in which similar participants had to write out the same narrative as the one used in the main study in at least 150 words. No time limit was fixed. All times were jutted down and then averaged to set a time limit for the study. The resultant mean, and thereby the time limit, was 14 minutes. Following Ellis and Yuan (2004) and Yuan and Ellis (2003), this procedure was implemented so as to curb large scale on-line planning. During task execution, the picture set remained accessible for the participants in this group.

Similarly, the - Here-and-Now planners were allowed to plan their upcoming narratives in 10 minutes with the provision of, and pursuing removal of, sheets of paper for note-taking, while looking at the picture set. However, the notes and the picture set were immediately removed after the pre-task planning stage. The participants in this group had 14 minutes to narrate the story in at least 150 words in written form. The only difference between this group and + Here-and-Now planners was that the former had to retrieve the story from their memory, while the latter had recourse to the picture story during task completion.

The + Here-and-Now no-planners had only 50 seconds to just make out the story in the pictures; no pieces of paper were provided for note-taking. Pursuant to the pre-task planning stage, with the provision of answer sheets, the participants commenced narrating the story while looking at the picture set. The written narratives had to be completed in 14 minutes and had to be at least 150 words.

The - Here-and-Now no-planners were allowed only 50 seconds to make sense of the story narrated by the picture set. No note-taking was done during this stage. Subsequently, the picture sets were removed, forcing the participants to retrieve and narrate the story from their memory. The participants in this group had to write at least 150 words in 14 minutes.

\section{Data Analysis}

In order to run the measures of production, all the narratives produced were typewritten in MS word documents and then coded by the researchers. In order to assess grammatical accuracy, three production measures were utilized: the percentage of error-free clauses (EFC), the number of errors per 100 words (NER), and target-like use of English articles (TLU). These measures reflected those implemented in previous studies of planning (e.g., Ellis \& Yuan, 2004, Foster \& Skehan, 1996; Ishikawa, 2007; Sangarun, 2005; Yuan \& Ellis, 2004). The first two indices, EFC and NER, are textbook examples of global grammatical accuracy measures in planning research, whereas the last measure was a specific measure of accuracy. The reason for the inclusion of EFC and NER was the argument made by Foster \& Skehan (1996) who recommended global measures over specific measures of accuracy inasmuch as the former deal in all contributory influences on error and correctness, while the latter do not. The third measure of accuracy was target-like use of articles which reflects the assumption that greater linguistic complexity is latched onto greater functional complexity (Givon, 1985) which, due to the absence of shared context, can be captured in the form of greater accuracy of articles (Robinson, 1995). In this regard, misspellings between a and an were ignored. The number of errors per 100 words was initially used by Mehnert (1998) in order to compensate for the shortcoming of error-free clauses which do not differentiate between clauses with one or more errors. T-units were taken as the clauses which encompassed a main clause in addition to any subordinate clauses (Richards, Platt, \& Weber, 1985). Sentence fragments were not regarded as T-units. Clauses were operationalized as those which had finite verbs (Polio, 1997).

An error was operationalized as any deviation in syntax, morphology and lexical choice, but not in punctuation or capitalization following Ellis \& Yuan (2004). EFC was assessed through the calculation of the number of error-free clauses divided by the total number of clauses multiplied by 100 .

Complexity indices consisted of two production measures: the number of S-nodes per T-unit (S-nodes/T), and the number of clauses divided by the number of T-units (C/T). Following Mehnert (1998), S-nodes included both finite and nonfinite clauses. 
Lexical complexity was coded through the percentage of lexical to function words (L/F) and Mean Segmental Type-Token Ratio (MSTTR), capturing Ellis \& Yuan (2004), Malvern \& Richards (2002), Malvern, Richards, Chipere, \& Duran (2004) and Yuan \& Ellis's (2003) analyses. Hyphenated words were calculated as a single word and adverbs ending in - ly were considered as a lexical word (Gilabert, 2007; Ishikawa, 2007).

$\mathrm{L} / \mathrm{F}$ was the percentage of lexical words divided by the number of function words. Type/token ratio (TTR) has been an orthodox lexical complexity measure in task-based studies; however, what a good deal of studies have taken for granted is the fact that TTR is overly sensitive to sample size (Wolfe-Quintero, Inagaki \& Kim, 1998). Therefore, one viable measure of lexical variation deemed to be independent of text length was run, namely MSTTR. Following Ellis \& Yuan (2004) and Yuan \& Ellis (2003), for the calculation of this index of lexical complexity, each narrative was chunked into segments of 40 words and the Type-Token Ratio of each segment was computed by dividing the total number of words by the total number of different words in the segment. Subsequently, the MSTTR (Malvern \& Richards, 2002) was calculated by adding the mean score of the segments and dividing the total by the total number of segments in the text for each participant.

Fluency was established through the calculation of the number of dysfluencies and length of text (TXL). Hyphenated words were counted as one word (Gilabert, 2007; Ishikawa, 2007).

After coding of the data was completed by one of the researchers, $15 \%$ of the data was coded by a second rater. An interrater reliability coefficient of greater than .82 was achieved for each measure. However, the reliability coefficients for the lexical complexity measures clocked lower. To obviate this problem, after a discussion session between the researchers and the independent rater, the data for these measures were re-coded. This time, the inter-rater reliability reached .84 and .81 for MSTTR and the percentage of lexical to function words, respectively.

As regards the dataset, the normal distribution of the four groups' scores was tested in terms of skewness, kurtosis, the test for normality, namely the Shapiro-Wilk test, and tests of homogeneity of variance. Moreover, boxplots were generated so that outliers could be detected. In cases of normal distribution of scores, two-way between subjects ANOVAs were run for which main effects and partial eta squared (Cohen, 1988) were reported $(0.01=$ small, $0.06=$ medium, $0.14=$ large). In cases of nonnormal distribution of scores or of heterogeneity of variance, two-way between subjects ANOVA's nonparametric equivalent, namely the Kruskal-Wallis test was run.

\section{RESULTS}

The descriptive statistics for the measures of grammatical accuracy, syntactic complexity, lexical complexity, and fluency are presented in Table 2 .

TABLE 2

DESCRIPTIVE STATISTICS FOR GRAMMATICAL ACCURACY, SYNTACTIC COMPLEXITY, LEXICAL COMPLEXITY, AND FLUENCY ACROSS THE FOUR GROUPS

\begin{tabular}{|c|c|c|c|c|c|}
\hline \multirow[t]{2}{*}{ Dependent variables } & & \multicolumn{2}{|l|}{ No planning } & \multicolumn{2}{|l|}{ Planning } \\
\hline & & Here-and-Now & There-and-Then & Here-and-Now & There-and-Then \\
\hline \multicolumn{6}{|l|}{ Accuracy } \\
\hline \multirow[t]{2}{*}{$\%$ of EFC } & Mean & 69.71 & 68.92 & 74.57 & 72.82 \\
\hline & SD & 10.07 & 9.69 & 13.05 & 12.27 \\
\hline \multirow[t]{2}{*}{ NER } & Mean & 8.73 & 8.96 & 7.90 & 8.00 \\
\hline & SD & 2.34 & 2.17 & 2.27 & 1.97 \\
\hline \multirow[t]{2}{*}{$\%$ of TLU } & Mean & 63.57 & 70.70 & 68.53 & 67.34 \\
\hline & SD & 10.64 & 10.98 & 9.75 & 9.80 \\
\hline \multicolumn{6}{|l|}{ Syntactic Complexity } \\
\hline \multirow[t]{2}{*}{ S-nodes per T-unit } & Mean & 1.40 & 1.37 & 1.58 & 1.67 \\
\hline & SD & .18 & .13 & .16 & .15 \\
\hline \multirow[t]{2}{*}{ Clauses per T-unit } & Mean & 1.17 & 1.17 & 1.22 & 1.28 \\
\hline & SD & .08 & .05 & .07 & .08 \\
\hline \multicolumn{6}{|l|}{ Lexical complexity } \\
\hline \multirow[t]{2}{*}{$\mathrm{L} / \mathrm{F}$} & Mean & 75.05 & 70.26 & 73.76 & 74.35 \\
\hline & SD & 7.59 & 8.04 & 9.21 & 8.89 \\
\hline \multirow[t]{2}{*}{ MSTTR } & Mean & .76 & .78 & .80 & .78 \\
\hline & SD & .05 & .07 & .06 & .04 \\
\hline \multicolumn{6}{|l|}{ Fluency } \\
\hline \multirow[t]{2}{*}{ Dysfluencies } & Mean & 8.26 & 9.89 & 6.15 & 8.91 \\
\hline & SD & 2.70 & 2.65 & 1.83 & 1.68 \\
\hline \multirow[t]{2}{*}{ TXL } & Mean & 138.93 & 132.93 & 157.74 & 147.90 \\
\hline & SD & 22.66 & 20.78 & 15.39 & 18.34 \\
\hline
\end{tabular}

The Shapiro-Wilk test showed that the data for the percentage of error-free clauses, the number of errors per 100 words, the number of S-nodes per T-unit, the number of clauses per T-unit, MSTTR, and the number of dysfluencies in the text were shown to be normal. That leaves the data for percentage of targetlike use of English articles and the percentage of lexical to function words for which data were found to be nonnormal. Hence, with respect to the former, two-way between subjects ANOVAs were conducted (Table 3). As regards the latter, the two-way between subjects ANOVA's equivalent, namely the Kruskal-Wallis test (Table 4) was conducted ensued by the Mann-Whitney U tests 
(Table 5).

TABLE 3

RESULTS OF TWO-WAY BETWEEN-SUBJECTS ANOVAS FOR GRAMMATICAL ACCURACY, SYNTACTIC COMPLEXITY, LEXICAL COMPLEXITY, AND FLUENCY ACROSS THE FOUR GROUPS

\begin{tabular}{|c|c|c|c|c|c|c|c|}
\hline $\begin{array}{l}\text { Independent } \\
\text { variables }\end{array}$ & Measures & SS & df & MS & F-Value & Sig. & $\begin{array}{l}\text { Partial Eta } \\
\text { Squared }\end{array}$ \\
\hline \multirow[t]{9}{*}{ Planning time } & $\%$ of EFC & 589.278 & 1 & 589.278 & 4.539 & $.035^{*}$ & .037 \\
\hline & NER & 24.663 & 1 & 24.663 & 5.122 & $.025^{*}$ & .041 \\
\hline & $\%$ of TLU & n.a & n.a & n.a & n.a & n.a & n.a \\
\hline & S-nodes per T-unit & 1.804 & 1 & 1.804 & 69.748 & $.000 *$ & .371 \\
\hline & Clauses per T-unit & .188 & 1 & .188 & 31.568 & $.000 *$ & .210 \\
\hline & $\%$ of L/F & n.a & n.a & n.a & n.a & n.a & n.a \\
\hline & MSTTR & .009 & 1 & .009 & 2.522 & .115 & .021 \\
\hline & Dysfluencies & 73.282 & 1 & 73.282 & 14.421 & $.000^{*}$ & .108 \\
\hline & TXL & 8766.609 & 1 & 8766.609 & 23.198 & $.000^{*}$ & .163 \\
\hline \multirow[t]{9}{*}{ Context } & $\%$ of EFC & 49.900 & 1 & 49.900 & .384 & .536 & .003 \\
\hline & NER & .863 & 1 & .863 & .179 & .673 & .002 \\
\hline & $\%$ of TLU & n.a & n.a & n.a & n.a & n.a & n.a \\
\hline & S-nodes per T-unit & .023 & 1 & .023 & .876 & .351 & .007 \\
\hline & Clauses per T-unit & .019 & 1 & .019 & 3.103 & .081 & .025 \\
\hline & $\%$ of $\mathrm{L} / \mathrm{F}$ & n.a & n.a & n.a & n.a & n.a & n.a \\
\hline & MSTTR & 6.385 & 1 & 6.385 & .017 & .896 & .000 \\
\hline & Dysfluencies & 147.282 & 1 & 147.282 & 28.984 & $.000^{*}$ & .196 \\
\hline & TXL & 1926.403 & 1 & 1926.403 & 5.098 & $.026^{*}$ & .041 \\
\hline \multirow{9}{*}{$\begin{array}{l}\text { Planning time * } \\
\text { Context }\end{array}$} & $\%$ of EFC & 7070 & 1 & 7070 & 054 & 816 & 000 \\
\hline & NER & .133 & 1 & .133 & .028 & .868 & .000 \\
\hline & $\%$ of TLU & n.a & n.a & n.a & n.a & n.a & n.a \\
\hline & S-nodes per T-unit & .117 & 1 & .117 & 4.521 & $.036^{*}$ & .037 \\
\hline & Clauses per T-unit & .028 & 1 & .028 & 4.701 & $.032 *$ & .038 \\
\hline & $\%$ of $\mathrm{L} / \mathrm{F}$ & n.a & n.a & n.a & n.a & n.a & n.a \\
\hline & MSTTR & .008 & 1 & .008 & 2.230 & .138 & .018 \\
\hline & Dysfluencies & 9.878 & 1 & 9.878 & 1.944 & .166 & .016 \\
\hline & TXL & 113.021 & 1 & 113.021 & .299 & .585 & .003 \\
\hline
\end{tabular}

TABLE 4

RESULTS OF KRUSKAL-WALLIS TESTS FOR THE PERCENTAGE OF TLU AND THE PERCENTAGE OF L/F ACROSS THE FOUR GROUPS

\begin{tabular}{|l|l|l|l|}
\hline Dependent variables & Chi-Square & df & Asymp. Sig. \\
\hline \% of TLU & 6.652 & 3 & .084 \\
\hline \% of L/F & 6.648 & 3 & .084 \\
\hline \multicolumn{4}{|c|}{$*$ Statistically significant at p <..05 }
\end{tabular}

TABLE 5

RESULTS OF MANN-WHITNEY U TESTS FOR THE PERCENTAGE OF TLU AND THE PERCENTAGE OF L/F ACROSS THE FOUR GROUPS

\begin{tabular}{|c|c|c|c|c|c|}
\hline $\begin{array}{l}\text { Dependent } \\
\text { variables }\end{array}$ & Comparison & Mann-Whitney U & Wilcoxon W & $\mathrm{Z}$ & $\begin{array}{l}\text { Asymp. Sig. } \\
\text { (2-tailed) }\end{array}$ \\
\hline \multirow{2}{*}{$\%$ of TLU } & Planning vs. No planning & 1829.000 & 3659.000 & -.309 & .758 \\
\hline & Here-and-Now vs. There-and-Then & 1555.000 & 3446.000 & -1.700 & .089 \\
\hline \multirow[t]{2}{*}{$\%$ of $\mathrm{L} / \mathrm{F}$} & Planning vs. No planning & 1658.000 & 3488.000 & -1.174 & .240 \\
\hline & Here-and-Now vs. There-and-Then & 1608.500 & 3561.000 & -1.429 & .153 \\
\hline
\end{tabular}

$*=$ Statistically significant at $\mathrm{p}<.05$

As can be seen in Table 3, in terms of the percentage of error-free clauses, provision of pre-task planning time significantly fostered accuracy; nonetheless, the effect was not meaningful owing to the small effect size $(F(1,119)=$ $4.539, \mathrm{p}=.035, \eta \mathrm{p} 2=.037)$. However, no significant effect was registered as a function of manipulation of immediacy $(\mathrm{F}(1,119)=.384, \mathrm{p}=.536)$. Furthermore, the interaction between the two independent variables was found to be marginal (Planning time * Immediacy: $\mathrm{F}(1,119)=.054, \mathrm{p}=.816)$. The same holds as far as the second measure of accuracy, namely the number of errors per 100 words is concerned for planning time, immediacy, and their interaction $(\mathrm{F}(1,119)=5.122, \mathrm{p}=.025, \eta \mathrm{p} 2=.041, \mathrm{~F}(1,119)=.179, \mathrm{p}=.673$, Planning time * Immediacy: $\mathrm{F}(1,119)=.028, \mathrm{p}$ $=.868$, respectively). As regards the last measure of accuracy, the percentage of targetlike use of English articles, there was no significant difference across the groups of participants $(\mathrm{x} 2=6.652$, $\mathrm{df}=3, \mathrm{p}=.084$ ). Furthermore, Mann-Whitney $U$ tests did not show any significant differences in the no-planning vs. planning groups and Here-and-Now vs. There-and-Then groups $(\mathrm{z}=-.309, \mathrm{p}=.758, \mathrm{z}=-1.700, \mathrm{p}=.089$, respectively). In light of the significant effects of manipulation of pre-task planning time found by two of the measures on accuracy, the first null 
hypothesis was disconfirmed.

As is clear in Table 3, with respect to the first measure of syntactic complexity, the number of S-nodes per T-unit, the planning groups significantly outperformed their no-planning counterparts, the effect size of which was very large (F (1, $119)=69.748, p=.000, \eta p 2=.371)$. In spite of the fact that immediacy of time and space did not exert a significant influence $(\mathrm{F}(1,119)=.876, \mathrm{p}=.351)$, the interaction between pre-task planning time and immediacy significantly influenced performance; i.e., the effect of planning impinged on immediacy so much so that the planners' output was further promoted by the There-and-Then task (Planning time ${ }^{*}$ Immediacy: $F(1,119)=4.521, p=.036, \eta p 2=.037$ ). The same findings were borne out by the number of clauses per T-unit for planning, immediacy, and their interaction $(\mathrm{F}$ $(1,119)=31.568, \mathrm{p}=.000, \eta \mathrm{p} 2=.210, \mathrm{~F}(1,119)=3.103, \mathrm{p}=.081, \mathrm{~F}(1,119)=4.701, \mathrm{p}=.032, \eta \mathrm{p} 2=.038$, respectively). In the wake of these findings, the second null hypothesis was rendered untenable.

Concerning the lexical complexity measures, no significant differences were found across the groups of participants in terms of lexical to function words $(\mathrm{x} 2=6.648, \mathrm{df}=3, \mathrm{p}=.084)$. Furthermore, subsequent Mann-Whitney U tests did not show any significant differences in the planning vs. no planning groups $(\mathrm{z}=-1.174, \mathrm{p}=.240)$ and in Here-and-Now vs. There-and-Then groups $(\mathrm{z}=-1.429, \mathrm{p}=.153)$. As far as MSTTR is concerned, the difference across the groups of participants did not reach statistical significance for either planning time, immediacy, or their interaction $(\mathrm{F}(1,119)=2.522, \mathrm{p}=.115, \mathrm{~F}(1,119)=.017, \mathrm{p}=.896, \mathrm{~F}(1,119)=2.230, \mathrm{p}=.138)$. Hence, the third null hypothesis was confirmed.

Finally, fluency measures revealed significant main effects for both independent variables. Increments along planning time significantly reduced the number of dysfluencies in the text and encouraged lengthier texts with a moderate effect size for the former and a moderate one for the latter $(\mathrm{F}(1,119)=14.421, \mathrm{p}=.000, \eta \mathrm{p} 2=.108, \mathrm{~F}(1,119)=23.198, \mathrm{p}$ $=.000, \eta \mathrm{p} 2=.163$, respectively). Moreover, displacedness of time and space significantly increased dysfluencies in the text and shortened text length which was largely and minimally meaningful, respectively $(\mathrm{F}(1,119)=28.984, \mathrm{p}=.000$, $\eta \mathrm{p} 2=.196, \mathrm{~F}(1,119)=5.098, \mathrm{p}=.026, \eta \mathrm{p} 2=.041$, respectively). No significant interaction was found between the two independent variables in terms of the number of dysfluencies in the text and the length of text $(\mathrm{F}(1,119)=1.944, \mathrm{p}$ $=.166, \mathrm{~F}(1,119)=.299, \mathrm{p}=.585$, respectively). Therefore, the last null hypothesis was dispelled.

\section{DISCUSSION AND CONCLUSIONS}

Findings regarding grammatical accuracy have widely diverged in planning research. In the main, the findings of the present study converged on those which have found a diminutive impact of planning on L2 production in terms of accuracy (e.g., Ellis \& Yuan, 2004; Foster \& Skehan, 1996; Yuan \& Ellis, 2003). This may be due to the assumption that pre-task planning does not channel attention toward specific features of the code; hence, it does not facilitate focus on form. Even if it does, as Ortega (2005) has stated the effect of pre-task planning on accuracy is implicated, when higher proficiency levels are targeted.

As accuracy scores of groups of participants showed that those in the planning conditions outperformed those in the no-planning conditions in two of the measures (the percentage of error-free clauses and the number of errors per 100 words), this may be due to the assumption that some monitoring did take place during pre-task planning time; however, the processing load of on-line performance may have circumscribed some of the monitoring transpired. This is further advocated by Wendel (1997, as cited in Sangarun, 2005) who surmised that monitoring of output prior to task performance does not exert an influence on monitoring of output during execution of the task.

However, as the percentage of target-like use of English articles goes, there were no stable results. This finding may spring from the assumption that proper use of the article system may emerge relatively late in language development (Pourreza, 2005). So as the participants in the study were not from an advanced proficiency group, their slippage with regard to accurate use of English articles was evident.

Moreover, findings regarding the effect of manipulation of immediacy on accuracy converged on those of Gilabert (2007) regarding error-free clauses and percentage of target-like use of articles and partially with those of Ishikawa (2007).

Gilabert (2007) questions the sensitivity of general and specific measures of accuracy in registering subtle differences across simple and complex tasks. So he calls for the development of other more sensitive measures like those used by Gilabert (2007), percentage of self-repairs and the ratio of repaired to unrepaired speech.

It can also be argued that by and large Here-and-Now studies have been orally-oriented. Skehan (1998) argues that modality plays an incremental role in the amount of cognitive load and allocation of attention, as the real-time processing demands of spoken language leave little leeway for attention to form, whereas writing may give more space to learners to steer their attention to form. Thus, some monitoring may have taken place in both simple Here-and-Now and complex There-and-Then conditions which induced both groups to do equally well on accuracy measures.

As regards syntactic complexity, the findings of the present investigation aligned with those of previous research regarding syntactic complexity (Ellis \& Yuan; 2004; Foster \& Skehan, 1996; Ortega, 1999; Sangarun, 2005; Skehan \& Foster, 1997, 2005; Tavakoli \& Skehan, 2005; Yuan \& Ellis, 2003). It can be hypothesized that provision of pre-task planning time may give learners some leeway to think about the content and rhetorical organization of their output and encourage them to take risks and demonstrate their newly assimilated cutting-edge language features. On the other hand, manipulation of immediacy per se did not conduce to greater syntacticization which may have come about as the result 
of the monologic nature of the tasks that may have lowered the chances of gains in syntactic complexity or their limited proficiency. A surprising finding in the study was that despite the fact that manipulation of immediacy did not influence complexity of discourse, increments in task complexity along immediacy did further solidify the effect of provision of pre-task planning on syntactic complexity. This means that simultaneous manipulation of pre-task planning time and immediacy does impact the quality of language in the sense that the effect of provision of pre-task planning time is heightened by the increments in immediacy (There-and-Then condition).

This finding can be interpreted in terms of memory demands. The There-and-Then task forced differential memory demands on learners from those of the Here-and-Now task, as the participants in the There-and-Then groups had to commit the story to their memory and subsequently retrieve it from their memory so that they were able to generate a coherent narrative. This may have pushed them to ponder on the storyline of the picture set, to infer the liaisons between events, and to make larger pieces of information to ease memory encoding, storage, and retrieval, thereby implicating deeper semantic processing (Robinson, 1995).

In planning research, most studies have opted out of measuring lexical complexity which might be due to its elusive nature. In the present study, lexical complexity measures demonstrated diminutive effects occasioned by manipulation of planning time and immediacy on written performance. This may have transpired as a result of limited proficiency of learners which may have engendered a ceiling effect for lexicalization of output. Another bone of contention is the potential difference between lexical sophistication measures and lexical range measures. Ortega (1999) argues that previous research, which has found significant gains for lexical complexity as the result of planning, has run mostly lexical sophistication measures not lexical range measures. The present study conducted lexical range measures in lieu of lexical sophistication measures. Finally, the storyline of the picture series might have fettered the use of more lexicalized language, as lexical range may be enmeshed with the story narrated by the pictures.

Similarly, manipulation of immediacy did not significantly impact lexical complexity of L2 learners' production. Although the higher memory demands brought to bear by the There-and-Then task may have induced learners to try to retrieve the storyline and to cohere a text together, thereby implicating deeper semantic processing and creating more elaborated semantic representations, this mental effort after understanding meaning seemed to have been more directed at mobilizing more cutting-edge knowledge of grammar than at using more lexical words. A second possibility may be that the picture set did not call for more diverse lexical items.

Finally, the findings of the present study bore out those of earlier research with respect to the effect of pre-task planning on fluency, as fluency was promoted in the present study as a function of planning. The fact that pre-task planners generated longer texts in the present study points to the assumption that they had probably conceptualized their propositional content, rehearsed their message, and written to remember their message. Therefore, over the course of task completion, the planners were less incurred by the cognitive load exacted by task demands and were able to set their mind to producing a more embellished text, which contained more elaboration, details or interpretations. The other measure, the number of dysfluencies in the text, also showed that provided with planning time, learners may come up with newly developed plans through macro- and micro-planning. Then, having identified the problem spots, they either work on them or circumvent them. They may also review, rehearse, and memorize their notes. These strategies are expected to buy them time during on-line performance, as the cognitive load of real-time performance is mitigated. Therefore, dysfluencies during completion of task proper are expected to diminish.

Findings with respect to the effect of manipulation of immediacy on fluency of written production were consonant with those of previous +/- Here-and-Now studies (e.g., Gilabert, 2007; Rahimpour, 2002, 2007; Robinson, 1995). The findings of the present study endorsed the notion that the lesser memory demands triggered by the Here-and-Now task would go a long way in fostering fluency of production in terms of length of text and the number of dysfluencies. In the Here-and-Now task, in light of the conviction that the situational knowledge can be tapped into, memory demands were less taxing and there was no need for the construction of deeper semantic representations; thus, attention could be allocated to the production of a more fluent speech.

In general terms, the present study demonstrated that manipulation of pre-task planning time and immediacy influenced L2 written narrative production in terms of both quantity and quality. Quantitatively, both pre-task planning time and immediacy led to differential fluency gains. Qualitatively, syntactic complexity of written output was influenced by manipulation of pre-task planning time; moreover, although it did not affect syntactic complexity directly, increases in task complexity along immediacy were conducive to a greater propitious effect of pre-task planning time. This was the most interesting finding of the study, as it points up at a key synergistic effect of these two variables, i.e, in terms of syntactic complexity, their effects are contingent upon each other.

The findings of the present study lent strong empirical support for Skehan and Foster's Single Resource Limited Attentional Capacity Model (Skehan, 1998; Skehan \& Foster, 2001). Overall, the present investigation found strong empirical support for the former view of attention allocation policies, as higher complexity scores were not met with higher accuracy scores. It seems that learners had available attentional resources to allocate to only syntactic complexity with which accuracy could not keep pace. Therefore, accuracy and syntactic complexity seem to have been in competition for attention with no deteriorating effects for fluency. This runs counter to Robinson's (2001a, 2001b) claim that fluency and accuracy/complexity are in competition for attention.

Given the assumption that in view of their limited attentional resources, L2 learners can fall behind on at least one 
area of production (accuracy, complexity, or fluency), teachers should manipulate task features so that they could selectively channel learners' attention to the areas of production in which they fail. This is of import since previous research has shown that learners' limited attentional resources make them prioritize one aspect of production (meaning) over form (VanPatten, 2002). Therefore, if attention is not selectively channeled to strike a balance between the three areas of development (accuracy, complexity, and fluency), learners will progress in some areas at the expense of other areas of development.

From the foregoing, it seems that task-based research studies offer many avenues for research which could be explored so that the effects of different task features can be charted. It is hoped that through this line of research design features of tasks can be identified as much as possible so that tasks can be developed in ways to channel learners' attention to different aspects of production so that a balanced interlanguage could follow.

\section{APPENDIX A THE HERE-AND-NOW TASK}

Prompt for the Here-and-Now conditions (Here-and-Now \& No planning and Here-and-Now \& Planning): Begin the story like this: TODAY, the city is very polluted...
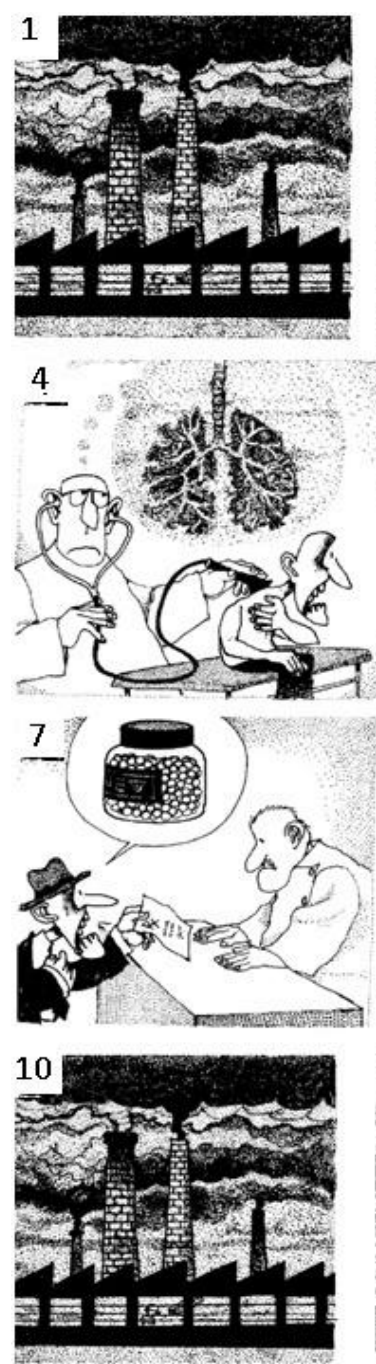
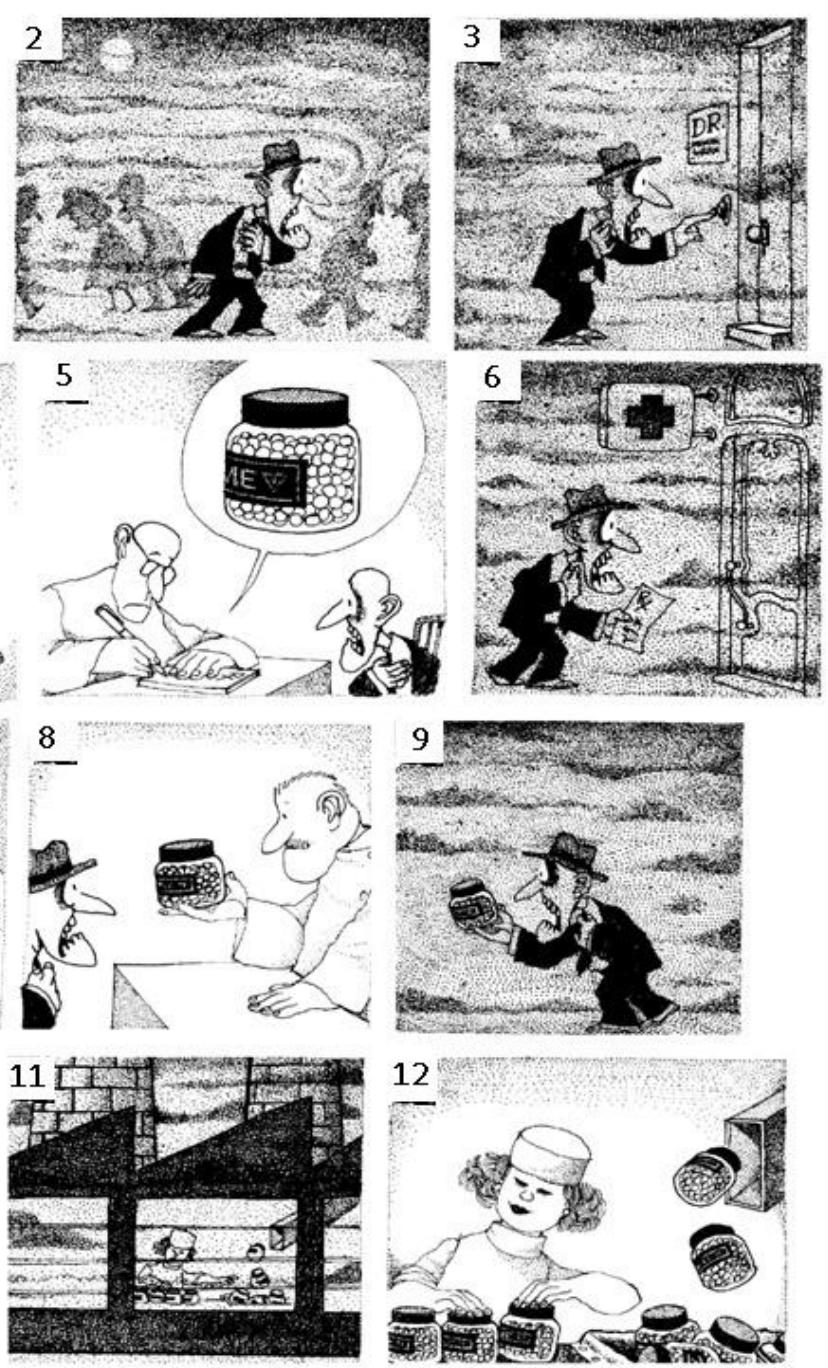

APPENDIX B THE THERE-AND-THEN TASK

Prompt for the There-and-Then conditions (There-and-Then \& No planning and There-and-Then \& Planning): BEGIN THE STORY LIKE THIS: Yesterday, the city was very polluted... 

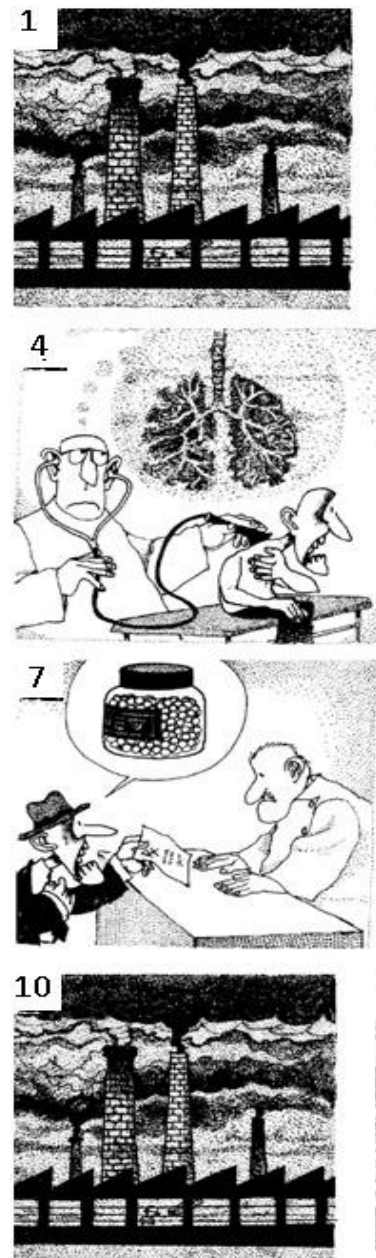
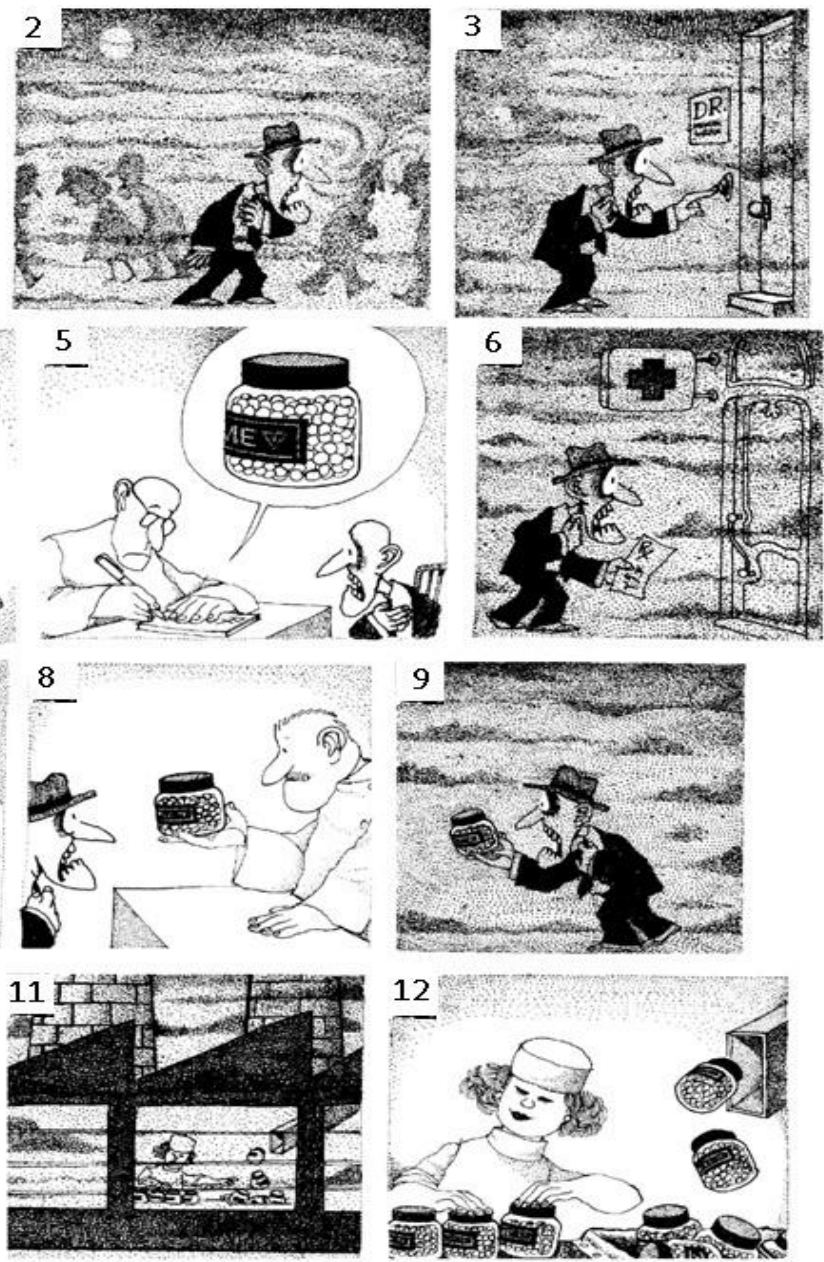

\section{REFERENCES}

[1] Cohen, J. (1988). Statistical power analysis for the behavioral sciences. New York: Academic Press.

[2] Ellis, R (Ed.). (2005). Planning and task performance in a second language. Amsterdam/ Philadelphia: John Benjamins.

[3] Ellis, R., \& Yuan, F. (2004). The effects of planning on fluency, complexity, and accuracy in second language narrative writing. Studies in second Language acquisition, 26, 59-84.

[4] Foster, P., \& Skehan, P. (1996). The influence of planning and task type on second language performance. Studies in Second Language Acquisition, 18, 299-323.

[5] Gilabert, R. (2007). The simultaneous manipulation of task complexity along planning time and [+/- Here-and-Now]: Effects on L2 oral production. In M. del Pilar Garcia-Mayo (Ed.), Investigating tasks in formal language learning. Clevedon, Avon: Multilingual Matters, 44-68.

[6] Givon, T. (1985). Function, structure, and language acquisition. In D. Slobin (Ed.), The crosslinguistic study of language acquisition: Vol 1. Hillsdale, NJ: Lawrence Erlbaum, 1008-1025.

[7] Huitt, W. (2003). The information processing approach. Educational Psychology Interactive. Valdosta, GA: Valdosta State University. http://www.edpsycinteractive.org/topics/cogsys/infoproc.html (accessed 20, 9, 2008).

[8] Hulstijn J., \& Hulstijn, W. (1984). Grammatical errors as a function of processing constraints and explicit knowledge. Language Learning, 34, 23-43.

[9] Ishikawa, T. (2007). The effect of manipulating task complexity along the [+/- Here-and-Now] dimension on L2 written narrative discourse. In M. del Pilar Garcia-Mayo (Ed.), Investigating tasks in formal language learning. Clevedon, Avon: Multilingual Matters, 136-156.

[10] Iwashita, N., McNamara, T., \& Elder, C. (2001). Can we predict task difficulty in an oral proficiency test? Exploring the potential of an information-processing approach to task design. Language Learning, 51(3), 401-436.

[11] Kawauchi, C. (2005). The effects of strategic planning on the oral narratives of learners with low and high intermediate L2 proficiency. In R. Ellis (Ed.), Planning and task performance. Amsterdam/ Philadelphia: John Benjamins, 143-164.

[12] Malvern, D., \& Richards, B. (2002). Investigating accommodation in language proficiency interviews using a new measure of lexical diversity, Language Testing, 19 (1), 85-104.

[13] Malvern, D., Richards, B., Chipere, N., \& Duran, P. (2004). Lexical diversity and language development: Quantification and assessment. New York: Palgrave Macmillan.

[14] Mehnert, U. (1998). The effects of different lengths of time for planning on second language performance. Studies in Second Language Acquisition, 20, 52-83. 
[15] Ortega, L. (1999). Planning and focus on form in L2 Oral Performance. Studies in Second Language Acquisition, 21, $109-148$.

[16] Ortega, L. (2005). What do learners plan? Learner-driven attention to form during pre-task planning. In R. Ellis (Ed.), Planning and task performance. Amsterdam/ Philadelphia: John Benjamins Publishing Company, 77-109.

[17] Pica, T. (1997). Second language teaching and research relationships: A North American view. Language Teaching Research, 1, 48-72.

[18] Polio, C. G. (1997). Measures of linguistic accuracy in second language writing research. Language Learning, 47, $101-143$.

[19] Pourreza, S. (2003). The non-generic uses of the English definite article by Iranian adult EFL learners. University of Tehran-Tehran.

[20] Prabhu, N. (1987). Second language pedagogy. Oxford: Oxford University Press.

[21] Rahimpour, M. (2002). Cognitive load, task complexity, and L2 oral discourse. In A.A. Rezaei (Ed.), The First Conference on Issues in English Language Teaching in Iran. Tehran: The University of Tehran Printing and Publishing Center, 89-102.

[22] Rahimpour, M. (2007). Task Complexity and Variation in L2 Learner's Oral Discourse. University of Queensland Working Papers in Linguistics, 1. http://www.espace.library.uq.edu.au/eserv/UQ:23699/RahimpourFINAL.pdf (accessed 12/5/2008)

[23] Richards, J., Platt, J., \& Weber, H. (1985). Longman dictionary of applied linguistics. London: Longman.

[24] Robinson, P. (1992). Discourse semantics, interlanguage negotiation and the lexicon. University of Hawaii Working Papers in ESL, 2I, 35-69.

[25] Robinson, P. (1995). Task complexity and second language narrative discourse. Language Learning, 45, 99-140.

[26] Robinson, P. (2001a). Task complexity, task difficulty, and task production: Exploring interactions in a componential framework. Applied Linguistics, 22 (1), 27-57.

[27] Robinson, P. (2001b). Task complexity, cognitive resources, and syllabus design: A triadic framework for examining task influences on SLA. In P. Robinson (Ed.), Cognition and second language instruction. Cambridge: Cambridge University Press, 287-318.

[28] Robinson, P. (2007). Criteria for classifying and sequencing pedagogic tasks. In M. del Pilar Garcia-Mayo (Ed.), Investigating tasks in formal language learning. Clevedon, Avon: Multilingual Matters, 7-26.

[29] Rouhi, A. \& Marefat, H. (2006). Planning time effect on fluency, complexity and accuracy of L2 output. Pazhuhesh-e Zabanha-ye Khareji, 27. 123-141.

[30] Salvador, J. (1985). Quinoterapia. Barcelona: Lumen.

[31] Sangarun, J. (2005). The effects of focusing on meaning and form in strategic planning. In R. Ellis (Ed.), Planning and task performance. Amsterdam/ Philadelphia: John Benjamins Publishing Company, 111-141.

[32] Skehan, P. (1998). A cognitive approach to language learning. Oxford: Oxford University Press.

[33] Skehan, P., \& Foster, P. (1997). Task type and task processing conditions as influences on foreign language performance. Language Teaching Research, 1 (3), 185-211.

[34] Skehan, P., \& Foster, P. (1999). The influence of task structure and processing conditions on narrative retellings. Language Learning, 49 (1), 93-120.

[35] Skehan, P., \& Foster, P. (2001). Cognition and Tasks. In P. Robinson. (Ed.) Cognition and second language instruction. Cambridge: Cambridge University Press, 183-205.

[36] Skehan, P., \& Foster, P. (2005). Strategic and on-line planning: The influence of surprise information and task time on second language performance. In R. Ellis (Ed.), Planning and task performance (pp. 193-216). Amsterdam/ Philadelphia: John Benjamins Publishing Company.

[37] Tavakoli, P., \& Skehan, P. (2005). Strategic planning, task structure, and performance testing. In R. Ellis (Ed.), Planning and task performance. Amsterdam/ Philadelphia: John Benjamins Publishing Company, 239-273.

[38] Ting, S.C.C. (1996). Planning time, modality and second language task performance: Accuracy and fluency in the acquisition of Chinese as a second language. The University of Queensland working papers in language and linguistics, 1, 31-64.

[39] VanPatten, B. (1992). Attending to content and form in the input: An experiment in consciousness. Studies in Second Language Acquisition, 12, 287-301.

[40] VanPatten, B. (2002). Processing instruction: An update. Language Learning, 52 (4), 755-803.

[41] Wenzell, V. (1989). Transfer of aspect in the English oral narratives of native Russian speakers. In H. W. Dechert \& M. Raupach (Eds.), Transfer in language production. Norwood, NJ: Ablex, 71-96.

[42] Wigglesworth, G. (2001). Influences on performance in task-based oral assessments. In M. Bygate, P. Skehan, M. Swain (Eds.), Researching pedagogic tasks: second language learning, teaching and testing. Harlow: Pearson Education Limited, 186-209.

[43] Wolfe-Quintero, K., Inagaki, S., \& Kim, H.Y. (1998). Second language development in writing: Measures of fluency, accuracy, and complexity. Honolulu, HI: Second Language Teaching and Curriculum Center, University of Hawaii at Manoa.

[44] Yuan F., \& Ellis, R. (2003). The effects of pre-task planning and on-line planning on fluency, complexity, and accuracy in L2 monologic oral production. Applied Linguistics, 24 (1), 1-27.

Ali Akbar Khomeijani Farahani received his B.A. in the English Language and Literature from the University of Tehran. He got his M.A. and Ph.D. in Linguistics from Leeds University. He is currently a faculty member at the University of Tehran. His research interests are Syntax, Discourse Analysis, and TBLT. He has been teaching Linguistics and English for more than 19 years.

Seyed Reza Meraji got his B.A. in the English Language and Literature from the University of Tehran. He earned his M.A. in TEFL from the University of Tehran. His areas of interest include task-based language teaching, feedback, and writing. 